\title{
Static, Portable and Smart Detection Of Water Quality In Panchayath Distribution Tank
}

\author{
I.Jeya Daisy, B.Vinoth Kumar
}

\begin{abstract}
The significant crunch in the Current world is Water pollution. It has created an abundant influence on the Environment. With the intention of the non-toxic distribution of the water and its eminence should be monitored at real time. This paper suggested the smart detection with low cost real time system which is used to monitor the quality of water through IOT(internet of things). The system entail of different sensors which are used to measure the physical and chemical parameters of the water. The quality parameters are temperature, $\mathrm{pH}$, turbidity, conductivity and Total dissolved solids of the water are measured. Commercially available products capable of monitoring such parameters are usually somewhat expensive and the data's are collected by mobile van. Using Sensor technology provides a cost-effective and pre-eminent reliable as they can provide real time output. The measured values from the sensors can be observed by the core controller. The controller was programmed to monitor the distribution tank on a daily basis to hour basis monitoring. The TIVA $C$ series is used as a core controller. The Controller is mounted on the side of the distribution tank.
\end{abstract}

Finally, the sensor data from the controller is sent to Wi-Fi module through UART protocol. Wi-fi Module is connected to a public Wi-Fi system through which data is seen by the locals who are all connected to that Wi-Fi network.

Index Terms: Water pollution, Quality testing, Wi-Fi module

\section{INTRODUCTION}

Water is a very essential resource required to sustain life. The quality of drinking water plays a significant role in the health of human beings. Poor quality water may lead to many waterborne diseases.

Even though it is the government's responsibility to ensure that clean water is delivered to its citizens, ever aging infrastructure, which is poorly maintained, and continual increase in population puts a strain on the supply of clean water. It is thus paramount to monitor the quality of water which will be used for consumption. Traditional water quality monitoring methods involve sampling and laboratory techniques. These methods are however time consuming and not very cost effective. There is thus a need for more extensive and efficient monitoring methods. Water quality monitoring can be achieved through microbial measurements as well as physiochemical measurements. Physiochemical parameters include electrical conductivity, $\mathrm{pH}$, turbidity, temperature, and TDS. These parameters are analysed rapidly and reduced the cost than the microbial parameters. Commercially available products capable of monitoring such parameters are usually bulky and quite expensive.. In our project the development of a low-cost, wireless, multi-sensor

Revised Manuscript Received on December 22, 2018.

I.Jeya Daisy, Anna University, Kumaraguru college of Technology,Coimbatore,India

Dr.B.Vinoth Kumar,Anna University,Dr.Mahalingam college of Engineering and Technology,Coimbatore,India. 西 network for measuring the physicochemical water parameters; enabling real-time monitoring, is presented

\section{II.EXISTING SYSTEM}

Fiona Regan, Antóin and Audrey designed smart water quality monitoring system. In the system they used water quality smart sensors. This system is highly scalable, faster and user friendly, but it is costly because of smart sensors and sensors size are not unwavering for water tap.ZulhaniRasin and Mohd Rizal Abdullah developed a water quality monitoring system using Zigbee based wireless sensor network. In this system the high power Zigbee is used and it can be applied to small area and the base station is essential for data storage. NazleeniSamihaHaron, MohdKhuzaimi B Mahamad, Izzatdin Abdul Aziz, MazlinaMehat developed a water quality monitoring system, sensors datas are collected by the data kit which process through GSM modem. This system is not reliable for long distance also it will apply to only single unit of water source. AN Ning., designed monitoring system for water quality. In this system the water quality sensors collect data, from industrial water and municipal water storage, are gathered at the sub-station at which the data are processed. But the drawback is that it didnot offer real time monitoring of water parameters. Qiao Tie-Zhu, Song Le projected Online Monitoring System which is based on GPRS. This process is mainly developed for monitoring the water of ponds or lake.

\section{PROPOSED SYSTEM}

Fig 2.1 shows the block diagram of water quality testing system. In this system, the quality parameters are gathered by sensors. The measured data's are connected to the TIVA $\mathrm{C}$ series .Through the UART module, the data's are published by Wi-Fi module. The panchayath officers will check the quality of water in the distribution tank through the app. The real time monitoring is hour or daily basis depends upon the requirement.

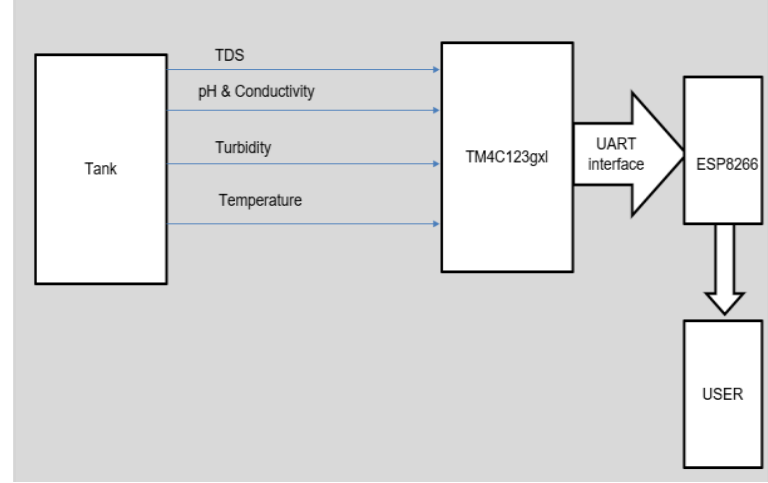

Fig2.1 Block Diagram

.

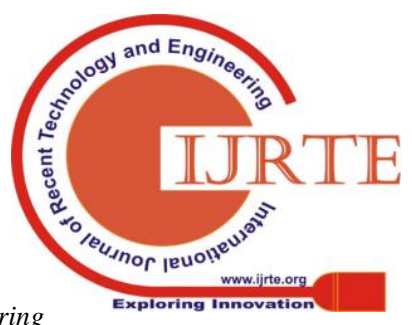




\section{Static, Portable and Smart Detection Of Water Quality In Panchayath Distribution Tank}

\subsection{QUALITY PARAMETERS AND HUMAN HEALTH}

The quality parameters are listed out and they are $\mathrm{pH}$, conductivity, Turbidity, temperature and Total dissolved solids. The quality parameters should be in normal level. The excessive level leads to affect the human health. So noted that these parameters are essential parameters to check the quality of water. Eye irritation and exacerbation of skin disorders have been subordinated with $\mathrm{pH}$ values which is above 11 . The $\mathrm{pH}$ is between $10-12.5$ caused the hair fibres to swell. The gastrointestinal irritation may also occur. The conductivity raises since the existence of chloride, nitrate and phosphate. An oil spill tends to reduce the conductivity. Turbidity can provide shelter and food for pathogens. Regrowth of pathogens in the distribution system causes the gastroenteritis. If the drinking water contains the total dissolved solids exceeding the limit, might cause the weakness, scouring, reduced production, bone degeneration and death.

\subsection{SENSORS}

\subsection{1 pH ELECTRODE}

Most often used $\mathrm{pH}$ electrode is the glass electrode which is made up of glass tube ended with glass bubble. The electrode is filled with buffered solution of chlorides in which silver wire covered with silver chloride is plunged. The $\mathrm{pH}$ of internal solution varies-for example, it can be 1 (or) 7.Dynamic part of the electrode is the glass bubble. While tube has strong and thick walls, bubble was made as thin. Surface of the glass is protonated by both internal and external solution till equilibrium is achieved. Each sides of the glass are charged by the adsorbed protons, this charge is responsible for potential difference. This potential is inversely proportional to the $\mathrm{pH}$ difference between solutions on both sides of the glass. Fig 3.2.1 shows the $\mathrm{pH}$ electrode.

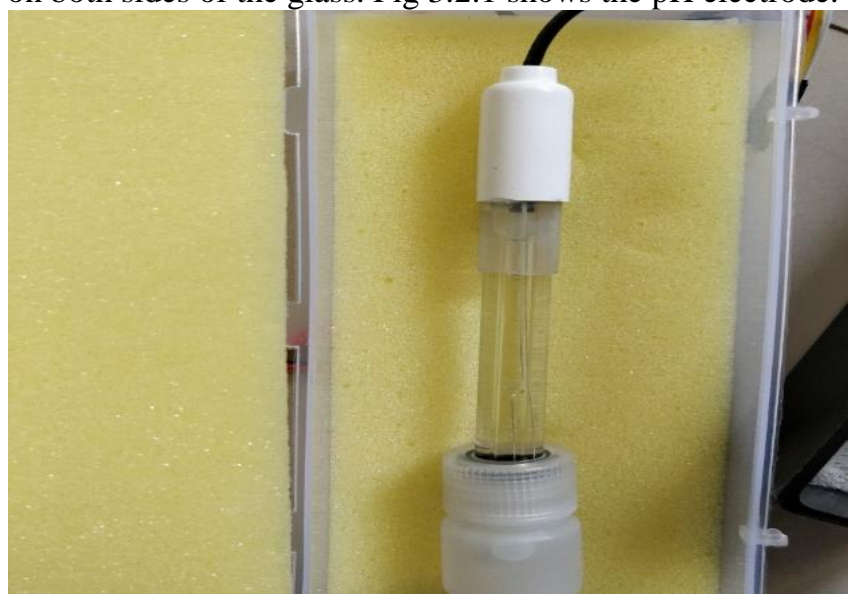

Fig 3.2.1 pH Electrode

\section{Specifications}

- $\quad$ Measuring Range 0-14 pH

- $\quad$ Accuracy $\pm 0.1 \mathrm{pH}$

- $\quad$ Response time $\leq 1 \mathrm{~min}$

- Operating Voltage 9V DC

Compensation relation for temperature and $\mathrm{pH}$

$\mathrm{pH}_{\mathrm{c}}=\mathrm{pH}-\left(\left(\mathrm{T}-\mathrm{T}_{\mathrm{o}}\right)\left(\mathrm{pH}_{\mathrm{o}}-\mathrm{pH}\right) * 0.003\right)$ where $\mathrm{T}_{\mathrm{o}}=24^{\circ} \mathrm{C}$

$\mathrm{pH}_{\mathrm{o}}=7$

\subsubsection{CONDUCTIVITY ELECTRODE}

The conductivity of water is an indication of the amount of ions and/or free flowing electrons that are present for the conduction of electricity. The conductivity sensor is designed using the two- or four electrode method is based on Ohms law. With a known resistor, voltage and current, the resistance of the water solution can be calculated accordingly. This calculation also requires the cell constants which are the length and area of the water sample. The resistance of the water is measured by using two or four electrodes with a known cell constant. Cell constants usually range from about $0.1 \mathrm{~cm}-1$ to $10 \mathrm{~cm}-1$, where higher cell constants work more effectively for higher conductivity solutions. To determine the resistance between the electrodes, a voltage was applied across the electrodes. The two-electrode method is considered in this project as it is easier to maintain and more economical. Conductivity electrode is also used in determining the total dissolved salts (TDS). The content of all inorganic and organic substances in a liquid in molecular, ionized or micro-granular suspended form is called Total Dissolved Solids (TDS). Though TDS is not a prime pollutant, TDS is used as an indication of aesthetic characteristics of drinking water and as an indicator of the presence of a broad array of chemical contaminants.

Gravimetric and conductivity are the two important methods for used to find the total dissolved solids. Gravimetric methods are the more exact methods and they involve evaporating the liquid solvent and taking the mass of residues left. This is the best method generally, but it is time-consuming. Concentration of dissolved ionized solids in the water is directly related to the electrical conductivity of water. Ions in the dissolved solids in water generate the ability for that water to conduct electrical current, which is measured by a TDS meter or conventional conductivity meter. Conductivity generally provides an approximate value for the TDS concentration, usually to within ten-percent accuracy.

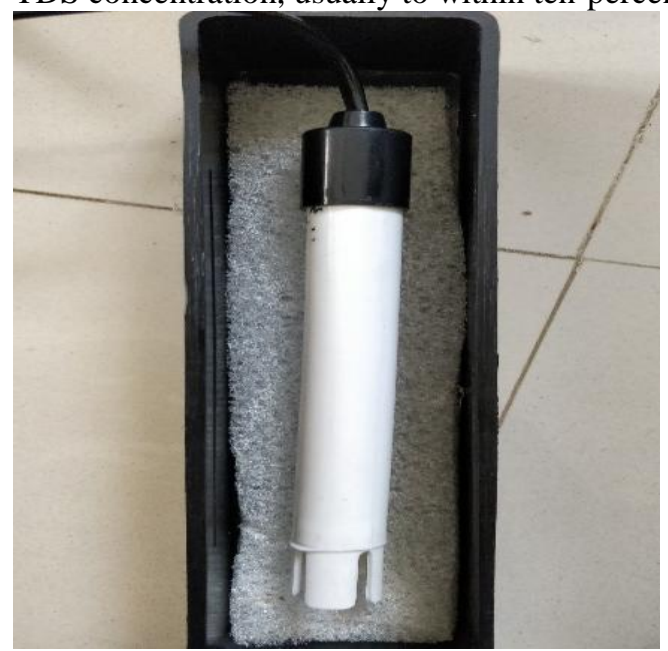

Fig3.2.2 Conductivity sensor 


\section{Specifications}

- Conductivity Cell Constant: 1.0

- Accuracy $\pm 5 \%$ of range

- $\quad$ operating Voltage $3.3 \mathrm{~V}$

\section{Compensation factor}

$$
\begin{array}{ll}
\alpha=\frac{\mathrm{G}_{\mathrm{T}}-\mathrm{G}_{\mathrm{TRef}} \cdot 100 \% /{ }^{\circ} \mathrm{C}}{} & \mathrm{G}_{\mathrm{TRef}}(\mathrm{T}-\mathrm{TRef}) \\
\mathrm{T} \quad= & \text { usually used temp } \\
\mathrm{T}_{\text {Ref }}= & \text { Reference temp } \\
\mathrm{G}_{\mathrm{T}} \quad=\text { measured conductivity at } & \text { Temperature } \\
\mathrm{G}_{\mathrm{TRef}}= & \text { measured conductivity at } \\
& \text { Reference temperature }
\end{array}
$$

\subsubsection{TURBIDITY SENSOR}

Turbidity sensors measure the amount of light that is scattered by the suspended solids in water. As the amount of total suspended solids (TSS) in water increases, the water's turbidity level (and cloudiness or haziness) increases. Turbidity Sensor uses the principle of IR transmitter and receiver. It measures based on the amount of signal received by the receiver. As more signals are scattered, turbidity level of water increases.

Excessive turbidity, or cloudiness, in drinking water is aesthetically unappealing, and may also represent a health concern. Turbidity can provide shelter and food for pathogens. Regrowth of pathogens in the distribution system is promoted if the turbidity is not removed, leading to waterborne disease outbreaks, which have caused significant cases of gastroenteritis throughout the world.

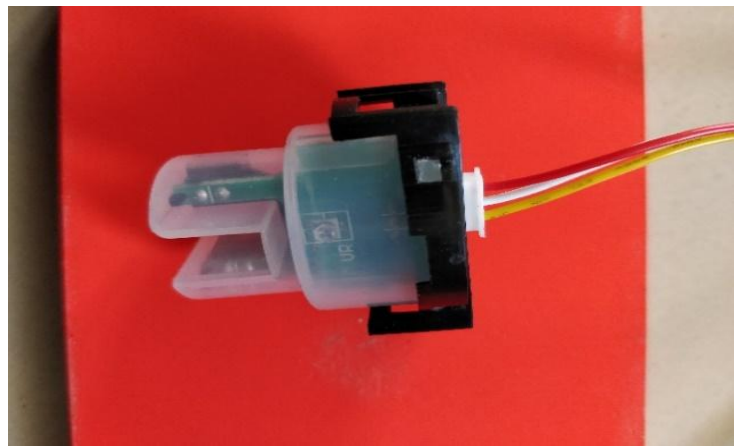

Fig 3.2.3 Turbidity sensor

3.2.2 Turbidity sensor

\section{Specifications}

- Measuring Range 0-100\%

- Accuracy $\pm 2 \%$

- Operating Voltage 3.3V DC

\subsubsection{TEMPERATURE SENSOR- DS18B20}

DS18B20 temperature sensors is One-wire devices that can measure temperature with a less amount of hardware and wiring. A digital protocol is used by the sensors for directly sending most accurate temperature readings to the development board without the requisite of an ADC or other other hardware. One-wire sensors had the different form factors like waterproof and high temperature probes. These factors are faultless for measuring temperature in several different schemes and applications. Although these sensors are one-wire protocol, you will add multiple
ISSN: 2277 - 3878, Volume-8, Issue-2S5, July 2019 of them connected to the same pin and read all of its temperature values independently.

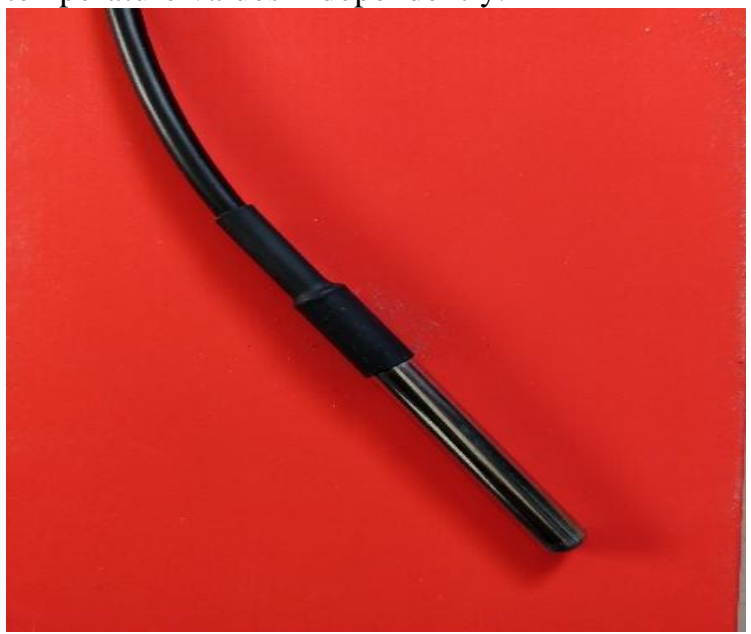

Fig 3.2.4. Temperature sensor DS18B20

\section{Specifications of DS18B20 \\ $>$ Operating Range $-55^{\circ} \mathrm{C}$ to $125^{\circ} \mathrm{C}$ \\ $>$ Accuracy $\pm 0.5^{\circ} \mathrm{C}$ \\ $>$ Operating Voltage $3.0 \mathrm{~V}$ to $5.5 \mathrm{~V} \mathrm{DC}$ \\ $>12$ bit Selectable resolution}

\subsection{CORE Controller - TM4C123 MCU}

The controller used is Tiva TM4C123gxl. Tiva C series is an open-source microcontroller, designed to make the development of project easy, efficient and more accessible. It has 14 digit al I/O pins and 6 analog pins and has two output pins of $3.3 \mathrm{~V}$ and $5 \mathrm{~V}$. The Arduino is powered via USB cable or an external power source via the adapter. The Arduino also has a USB to serial converter that helps in communicating to the computer via the USB. The Arduino is capable of reading $0-5 \mathrm{~V}$ of input voltage and capable of supplying output voltage of maximum range of $5 \mathrm{~V}$. The analog pin can be used as digital pins if any need arises.

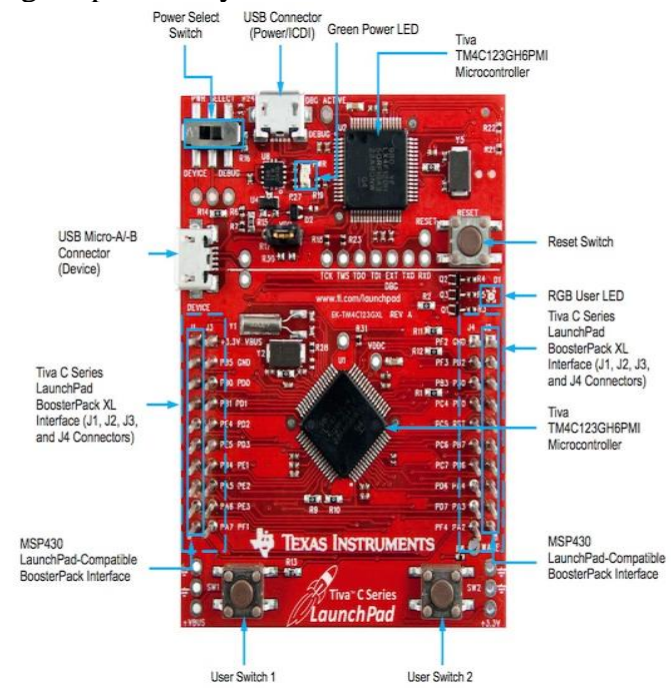

Fig 3.3.1 TM4C123 MCU

\subsubsection{Node MCU}

It is an open source IOT platform. It contains firmware which will run on the ESP8266 Wi-Fi SOC from Espressif Systems, and hardware which is based on the ESP-12 module. The term

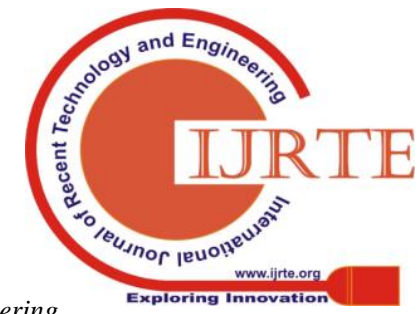




\section{Static, Portable and Smart Detection Of Water Quality In Panchayath Distribution Tank}

"NodeMCU" by default refers to the firmware rather than the dev kits. The firmware uses the Lua scripting language. It is based on the eLua project and built on the Espressif Non-OS SDK for ESP8266. It uses many open source projects, such as lua-cjson, and spiffs

\subsubsection{Specifications}

- Wi-Fi Module - ESP-12E module similar to ESP-12 module but with 6 extra GPIOs.

- USB - micro USB port for power, programming and debugging

- $\quad$ Headers - 2x 2.54mm 15-pin header with access to GPIOs, SPI, UART, ADC, and power pins

- $\quad$ Misc - Reset and Flash buttons

- $\quad$ Power $-5 \mathrm{~V}$ via micro USB port

- Dimensions $-49 \times 24.5 \times 13 \mathrm{~mm}$

- $\quad$ Operating Voltage 3.0-3.6V

- $\quad$ Wi-Fi $2.4 \mathrm{GHz}$, support WPA/WPA2

- $\quad$ Integrated TCP/IP protocol stack

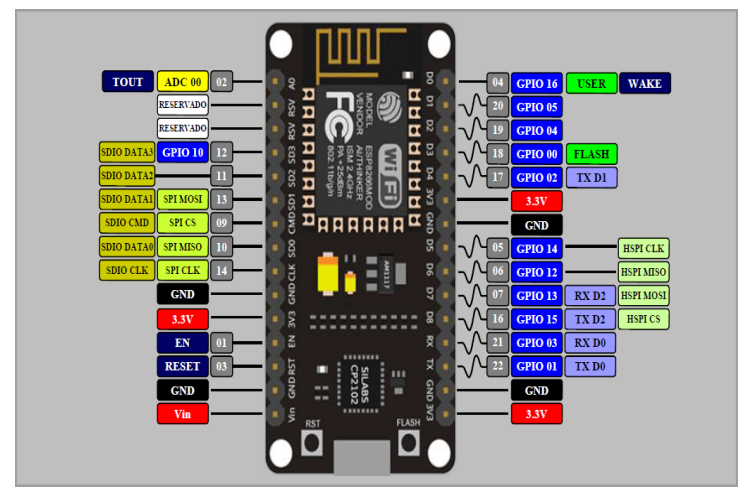

Fig 3.3.1 Pin Layout

\subsection{INTERFACING}

\subsubsection{Sensors with core controller}

The $\mathrm{pH}$, turbidity and conductivity sensors are connected to the analog port of the Tiva controller and the temperature sensor is connected to its digital pin.

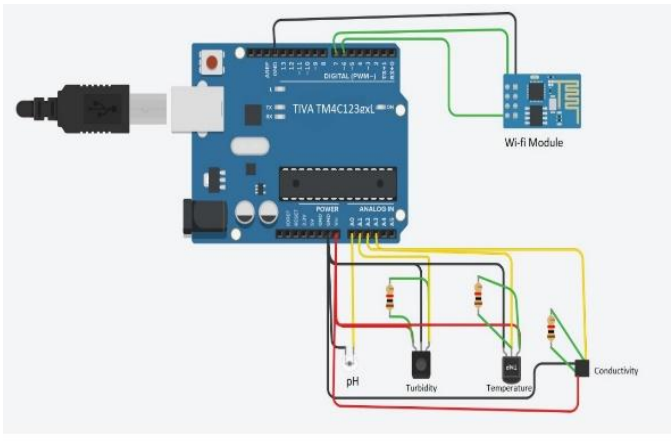

Fig 3.4.1 Interfacing With TIVA

\subsubsection{Interfacing Node MCU with TIVA}

The digital pin D2 and D3 are programmed as receiver and transmitter pin respectively. The pin D2 and D3 functions as UART port for the NodeMCU. These two pins are connected to the UART port of Tiva Arm controller for the transmission of data.

\section{TESTING OF WATER QUALITY}

The water quality monitoring system designed is tested for a period of two weeks. Three different sample of water is collected and stored in the tank for a period of 14 days. The three samples of water were taken from three different places (Saravanampatty, Gandhipuram, KCT hostel). These samples were kept in a vessel undisturbed for 14 days and the sensor efficiency is calculated from the result.

V Result

Fig 5 shows the results are obtained from Gandhipuram, Saravanampatti and KCT hostel distribution tanks.

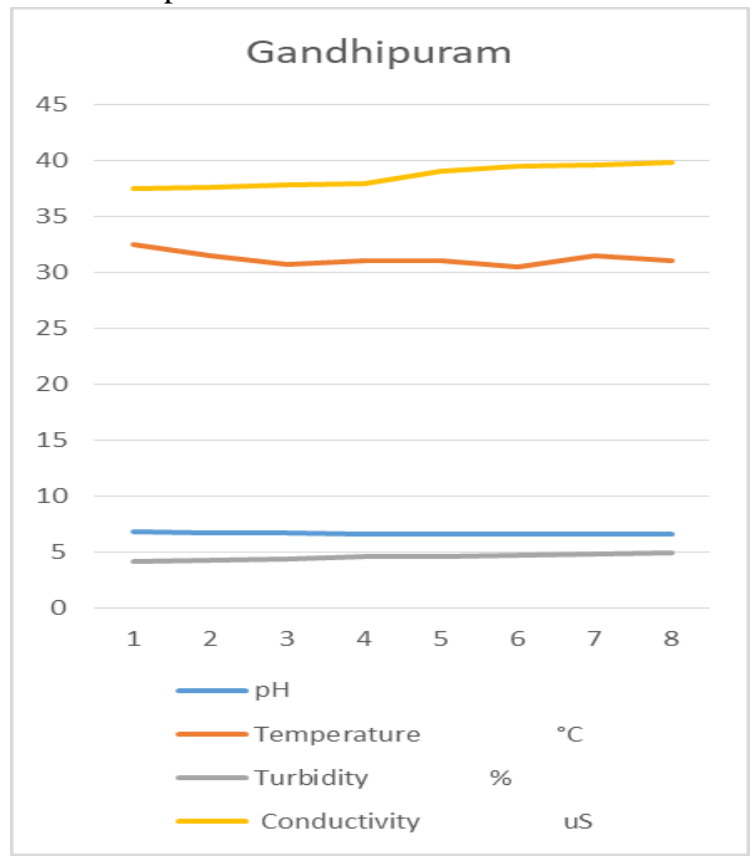

Fig 5.1 Report from Gandhipuram 


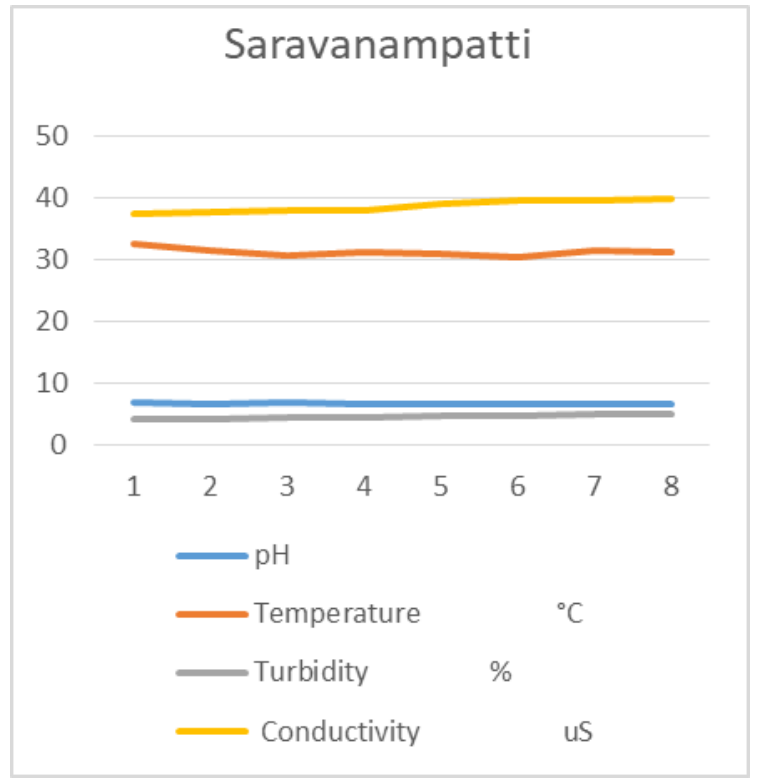

Fig 5.2 Report from Saravanampatti

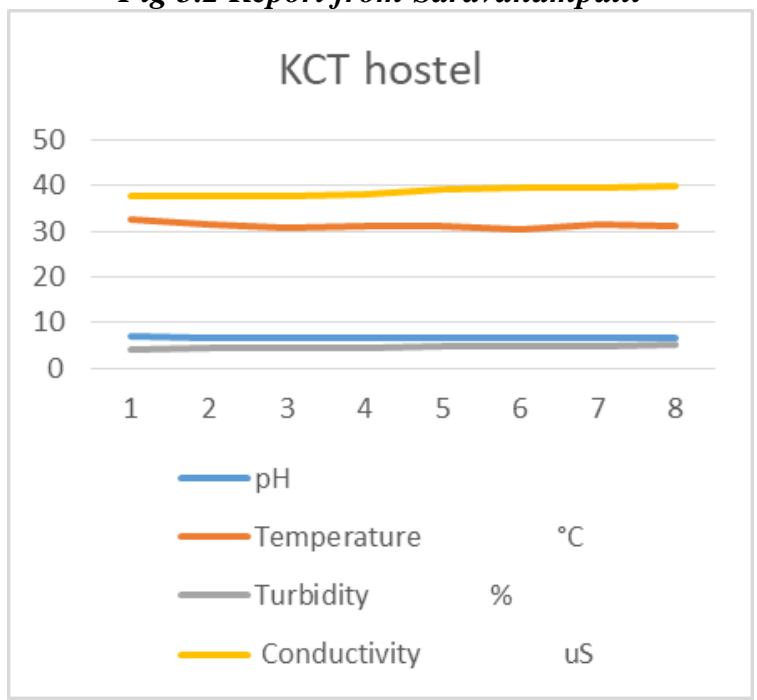

Fig 5.3 Report from KCT Hostel

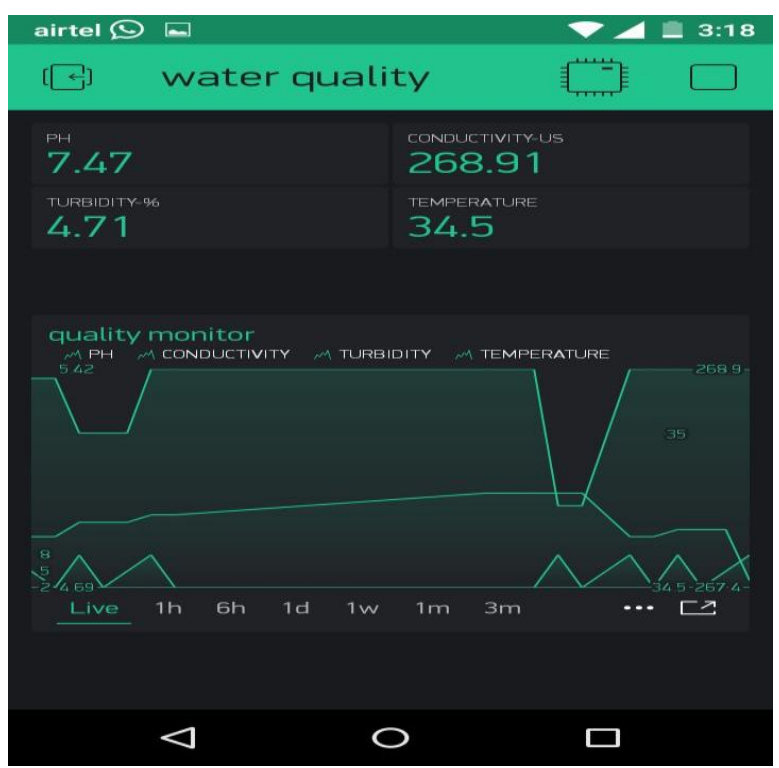

Fig 5.4 App Report
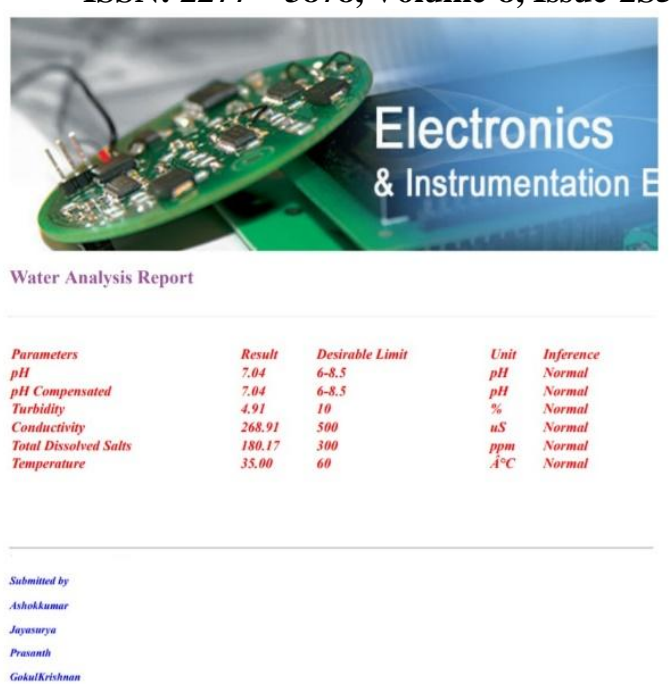

Fig 5.5 Web report

\section{CONCLUSION}

The final outcome of the project serves us in ensuring distribution of standard quality of water to all the locals. IoT technology to monitor the water quality has been implemented successfully. All sensors are working perfectly in the system. And these sensors will efficiently monitor and notify the user the quality of water to their hand phones using Wi-Fi technology. Further the usage of IOT module enables the controller to connect to the smart city's Wi-Fi and through that all the locals can have a look at the quality of water distributed to them.

The system will monitor the corporation water quality in distribution tanks using the implemented sensors and the data is stored using the cloud technology and the notification is successfully send to the users hand phone using Wi-Fi technology.

This system enables the user to easily view the water quality through their mobile phones using an android app, which is handy. Thus large amount of people is benefited through this system.

\section{VII.REFERANCE}

1. Nikhil Kedia, Water Quality Monitoring for Rural Areas- A Sensor Cloud Based Economical Project, in 1st International Conference on Next Generation Computing Technologies (NGCT-

2. 2015) Dehradun, India, 4-5 September

3. 2015. 978-1-4673-6809-4/15/\$31.00

4. C2015 IEEE

5. Jayti Bhatt, JigneshPatoliya, Iot Based Water Quality Monitoring System, IRFIC, $21 \mathrm{feb}, 2016$.

6. Michal lom, ondrejpriby\&miroslavsvitek, Internet 4.0 as a part of smart cities, 978-1-5090-1116-2/16/\$31.00 @2016 IEEE

7. Zhanwei Sun, Chi Harold Liu, ChatschikBisdikia, Joel W. Branch and Bo Yang, 2012 9th Annual IEEE Communications Society Conference on Sensor, Mesh and Ad Hoc Communications and Networks

8. SokratisKartakis, Weiren Yu, Reza Akhavan, and Julie A. McCann, 2016 IEEE First International Conference on Internet-of-Things Design and Implementation, 978-1-4673-9948-7/16 (C) 2016IEEE

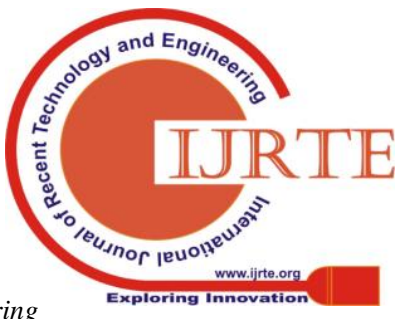


Static, Portable and Smart Detection Of Water Quality In Panchayath Distribution Tank

9. MithailaBarabde, shrutiDanve, Real Time Water Quality Monitoring System, IJIRCCE, vol 3, June 2015. AkankshaPurohit, UlhaskumarGokhale, Real Time Water Quality Measurement System based on GSM , IOSR (IOSR-JECE) Volume 9, Issue 3, Ver. V (May Jun. 2014)

10. Niel Andre cloete, Reza Malekian and Lakshmi Nair, Design of Smart Sensors for Real-Time Water Quality monitoring, (C2016 IEEE conference.

11. Tiva C-Series

a. http://www.ti.com/lit/ds/symlink/tm4c123gh6pm.pdf

12. Energia Guide

a. http://energia.nu/

13. NodeMcu interface and programming

14. http://www.nodemcu.com/index_en.html

15. HTML Guide

16. https://www.w3schools.com 